\title{
CAFÉ FILOSÓFICO: UMA METODOLOGIA DO ENSINO DE FILOSOFIA DO PIBID - PUC-GOIÁS
}

Polliana Pires do Carmo Alves Rocha ${ }^{1}$ Robilson Nascimento dos Santos ${ }^{2}$

O PIBID/PUC Goiás do subprojeto de Filosofia vem promovendo Cafés Filosóficos no Centro Integrado Cecília Meireles e Colégio Estadual Murilo Braga para os alunos do primeiro, segundo e terceiro ano do ensino médio. Antes de realizar a experiência nos cafés, realizamos uma pesquisa do livro: Ensinar Filosofia: um livro para professores, dos autores Renata Lima e Silvio Gallo. Com base neste, preparou e apresentou-se os Cafés Filosóficos. O contato com a filosofia deve, segundo os autores, proporcionar aos estudantes uma disciplina no pensamento. Esse contato com a experiência filosófica conduz os estudantes a outras possibilidades de ver o mundo. $O$ objetivo foi levar o aluno do ensino médio a criar suas próprias versões da realidade e do mundo que ele vive. Afinal pensar o ensino da filosofia no nível médio representa um grande desafio, isso devido a sua inconstância na educação brasileira, as universidades oferecem o curso de Filosofia, professores que já trabalham na área, estão preocupados e compreendem a necessidade de um debate sobre o ensino de Filosofia.

Uma das inquietações referente ao subprojeto é o preparo do professor para ensinar Filosofia. E, essa inquietação com o ensinar a Filosofia no nível médio da educação básica, pode ser observada tanto no aluno como nos professores. Do aluno pode surgir a ideia de que a Filosofia seja algo inalcançável, muito difícil e, muitas vezes, os alunos não entendem nada. Do professor a inquietação aparece no como fazer esses jovens com idades entre quinze a dezoito anos, pensar com autonomia. Como seria possível isso? Lendo textos filosóficos, exercitando a escrita, articulando conhecimento filosófico. Como motivar esses jovens? Muitas vezes surge a questão de que tudo isso é impossível, perda de tempo, os alunos não têm perspectiva ou são

\footnotetext{
${ }^{1}$ Coordenadora de Área do subprojeto de Filosofia e Professora Assistente da Pontifícia Universidade Católica de Goiás. prof.pollianapires@hotmail.com

${ }^{2}$ Acadêmico do curso de Filosofia e bolsista de Iniciação do PIBID/PUC - Goiás.
} 
limitados. Com essas considerações, precisou-se aprofundar nessa problemática e procurar as respostas e principalmente defender a permanência da disciplina no nível médio da educação básica e evidenciar porque a Filosofia é tão importante.

É fundamental entender como é o processo educativo e por que precisa de grande atenção. Violência nas escolas, falta de recursos, evasão escolar e tantos outros fatores, geram polêmicas quando são citados no meio educacional. $O$ professor tem um importante destaque no processo educacional, a relação professor-aluno, além da prática pedagógica, torna-se um referencial para o mesmo, onde são depositadas no professor suas projeções, um líder que vai influenciar a vida dos seus alunos.

É importante compreender melhor essa relação entre o professor e o aluno, na obra "O Banquete", de Platão, vê-se o método socrático: ironia e a maiêutica, em seus diálogos Sócrates interrogava seus interlocutores, levandoos a cair em contradição, percebendo em seguida sua ignorância (ironia), ao confrontar com o não saber, poder dar luz ás próprias ideias (maiêutica). Sócrates era o sujeito do conhecimento, sua relação com seus discípulos, lembra a relação professor-aluno, sendo o professor o possibilitador do diálogo, para que no espaço escolar haja a circulação da palavra.

Um dos objetivos foi partilhar a experiência da prática da filosofia no ensino médio, por meio dos Cafés Filosóficos no Centro de Ensino em Período Integral Cecília Meirelles (Aparecida de Goiânia - Goiás) e no Colégio Estadual Murilo Braga (Goiânia - Goiás), partilhando com os profissionais da área, novas metodologias de ensinar filosofia, conquistar seu espaço no meio escolar, inserir o aluno na experiência filosófica, para que ele possa criar suas próprias versões da realidade do mundo que vive.

\section{A ORIGEM DO CAFÉ FILOSÓFICO}

O primeiro Café Filosófico foi nas tardes de domingo na Praça da Bastilha em Paris na França em julho de 1992, no Café de Phares, organizado pelo Filósofo, professor, escritor e tradutor de francês, Marc Sautet (19471998). No seu livro "Um café para Sócrates - como a filosofia pode ajudar a compreender o mundo", conta a experiência com o Café Filosófico, a principal 
intenção era levar a Filosofia ao grande público, ajudando a buscar respostas para grandes questões existenciais. Como era de costume na França, as pessoas param para tomar um café, em lugares específicos e conversam sobre questões diversas, aos poucos essa ideia foi tomando grandes proporções e se espalhou por vários lugares. No Brasil, há registros de Café Filosófico realizado pela livraria Cultura, em São Paulo apresentado pela professora de Filosofia da USP Olgária Matos, em Campinas - São Paulo, cujo primeiro curador foi Renato Janine Ribeiro em 2003 e 2004. Este tem sido o formato exibido desde então na TV Cultura, com vários Curadores.

Com base nessas informações e como fonte de inspiração, através do PIBID (Programa Institucional de Bolsas de Iniciação á Docência) de Filosofia em parceria com a PUC - Goiás (Pontifícia Universidade Católica de Goiás), foram promovidos os Cafés Filosóficos no Centro de Ensino em Período Integral Cecília Meirelles, em Aparecida de Goiânia - Goiás. O PIBID é uma iniciativa para o aperfeiçoamento e a valorização da formação de professores para a educação básica. O programa concede bolsas a alunos de licenciatura participantes de projetos de iniciação à docência desenvolvida por Instituições de Educação Superior (IES) em parceria com escolas de educação básica da rede pública de ensino. Os projetos devem promover a inserção dos estudantes no contexto das escolas públicas desde o início da sua formação acadêmica para que desenvolvam atividades didático-pedagógicas sob orientação de um docente da licenciatura e de um professor da escola.

Para a efetivação do Projeto do Café Filosófico, utilizou-se alguns procedimentos, como: verificação dos temas dos Cafés Filosóficos de acordo com os conteúdos ministrados pelo professor de Filosofia das escolas; os bolsistas do PIBID de Filosofia fizeram reuniões na escola para a pesquisa sobre o tema abordado. A realização do café se dá nas dependências das escolas, onde é servido um saboroso lanche, momento de interação dos bolsitas com os alunos da escola, partilhando as experiências, valorizando a disciplina da Filosofia. No final do Café todos os arquivos como fotos e vídeos, são catalogados e alguns encontrados no canal CM da escola no Youtube. Os alunos da escola e os bolsitas do PIBID produziram textos que foram publicados no jornal AGORA, já na quinta, indo para a sexta edição, este jornal foi desenvolvido pelos bolsistas de Filosofia do PIBID da PUC-Goiás, 
juntamente com a coordenação do projeto e os professores supervisores, todos os arquivos servem como material de pesquisa para outros professores.

\section{A PRÁtiCA DA FILOSOFIA ATRAVÉS DO PROJETO DO CAFÉ FILOSÓFICO}

Quando o projeto do Café Filosófico foi idealizado, utilizou-se como base alguns livros. O primeiro foi: "Filosofia em sala de aula: teoria e prática para ensino médio", da professora de Filosofia e História da Educação da Faculdade de Educação da Unicamp, Lídia Maria Rodrigo, a autora já na primeira parte, menciona que a realidade da escola pública é bem crítica, com vários problemas e que estudantes de Filosofia e futuros professores precisam de preparo para enfrentar esses problemas. A professora Lídia tem bastante experiência como professora de Filosofia, e no seu livro ela destaca sobre a possibilidade de ensinar Filosofia nas escolas de massas, traçando objetivos, limites e justificando a necessidade de uma didática específica para o nível médio e como motivar estes alunos.

A autora menciona que o professor de Filosofia precisa elaborar sua própria didática, convidar a uma reflexão concreta do trabalho em sala de aula e tecer seu programa de ensino na disciplina de Filosofia, abrindo possibilidades. Para os professores de Filosofia é um grande desafio garantir o conhecimento filosófico, sem banalizá-lo, viabilizar para uma massa de estudantes com sérias deficiências culturais, acesso restrito a poucos. A importância das aulas expositivas com harmonia com as participativas, leitura de textos e exercícios e um plano de aula consistente todas essas ações precisam ser trabalhadas.

Outro livro pesquisado foi: "Ensinar Filosofia: um livro para professores", dos autores Silvio Gallo e Renata Aspis. Esses autores fundamentam o ensino de Filosofia a partir das concepções de Gilles Deleuze e Felix Guatarri, filósofos franceses e autores do Livro: "O que é a Filosofia?". Ensinar Filosofia não é tarefa fácil e nem mesmo pensar filosoficamente o ensino de Filosofia. O professor deve levar em conta as experiências dos alunos, sempre avançando e superando o senso comum e deve proporcionar aos estudantes o pensamento. Foram destacados no livro seis pontos de 
abordagem do ensino de filosofia, que são: Sensibilização que é a introdução do tema, podendo ser por meio de um vídeo, filme, música ou poesia, sensibilizar o aluno para o tema a ser estudado. Problematização, provocações com questões que envolvem o tema a ser estudado. Leitura filosófica, ou seja, fazer os alunos perceberem o problema levantado pelo filósofo, nesse momento da leitura o aluno entra em contato com o pensamento filosófico. História da Filosofia pode ser utilizada para que o aluno perceba o contexto histórico, determinado conceito ou ideia foi pensado por algum filósofo. Escrita filosófica, após ler o texto filosófico o aluno com um exercício fundamental, pode criar a sua versão do que leu, sempre utilizando os argumentos filosóficos. Por último, a Avaliação pode ser todas as atividades executadas na sala de aula ou em casa pelos alunos, a escolha do que será avaliado ou a maneira de avaliar, vai depender do que se pretende com avaliação e os professores tem que ter clareza nos seus objetivos.

E, finalmente o livro dos filósofos franceses Gilles Deleuze e Felix Guattari, "O que é a Filosofia? " Logo de início os filósofos abordam que a filosofia não é contemplação, reflexão e nem comunicação:

\begin{abstract}
A filosofia não contempla, não reflete, não comunica, se bem que ela tenha de criar conceitos para estas ações ou paixões. A contemplação, a reflexão, a comunicação não são disciplinas, mas máquinas de constituir Universais em todas as disciplinas. Os Universais de contemplação, e em seguida de reflexão, são como duas ilusões que a filosofia já percorreu em seu sonho de dominar as outras disciplinas (idealismo objetivo e idealismo subjetivo), e a filosofia não se engrandece mais se apresentando como uma nova Atenas e se desviando sobre Universais da comunicação que forneceriam as regras de um domínio imaginário dos mercados e da mídia (idealismo intersubjetivo) (DELEUZE; GUATARRI, 1992, p.15).
\end{abstract}

A Filosofia para os referidos autores cria conceitos, por isso que ela não é reflexão, nem contemplação e nem mesmo comunicação, estes âmbitos imperam os universais. Definição da Filosofia como criadora de conceitos, uma ação, uma atividade, um ato do pensamento, sendo que para o aprendizado da Filosofia isso é importante. Não basta só ensinar, é importante dar continuidade e fazer a própria experiência. Por isso que para os filósofos a definição é algo que paralisa o pensamento, conceito não é definição e a definição acaba com o conceito e quando perguntamos o que é? Não é definição, por que o conceito 
está sem movimento e a definição é universal. A tarefa da Filosofia é criativa, ao definir o filósofo como "amigo do conceito":

\begin{abstract}
O filósofo é amigo do conceito, ele é conceito em potência. Quer dizer que a filosofia não é uma simples arte de formar, de inventar ou de fabricar conceitos, pois os conceitos não são necessariamente formas, achados ou produtos. A filosofia, mais rigorosamente, é a disciplina que consiste em criar conceitos. $\mathrm{O}$ amigo seria o amigo de suas próprias criações? Ou então é o ato do conceito que remete à potência do amigo, na unidade do criador e de seu duplo? Criar conceitos sempre novos é o objeto da filosofia. É porque o conceito deve ser criado que ele remete ao filósofo como àquele que o tem em potência, ou que tem sua potência e sua competência. (...) Para falar a verdade, as ciências, as artes, as filosofias são igualmente criadoras, mesmo se compete apenas à filosofia criar conceitos no sentido estrito. Os conceitos não nos esperam inteiramente quietos, como corpos celestes. Não há céu para os conceitos. Eles devem ser inventados, fabricados, ou antes, criados, e não seriam nada sem a assinatura daqueles que os criam (DELEUZE; GUATARRI, 1992, p.13).
\end{abstract}

Ao pensarmos o projeto do Café Filosófico, principalmente a prática da Filosofia através desse projeto, o objetivo é que o aluno possa experimentar o pensar filosoficamente, criar conceitos e dar o movimento a Filosofia. Inventar suas próprias regras de fazer Filosofia, segundo uma maneira de confecção, um estilo que lhes seja próprio. Tal iniciativa permite vencer o receio diante da escrita, favorecendo um modo de expressão mais próximo dos seus movimentos, experimentar novas formas de pensar, seguindo os pensamentos dos filósofos, respeitando-os, mas sem reproduzi-los. A finalidade do projeto Café Filosófico, é que o aluno possa experimentar os pensamentos dos filósofos, dar o movimento á Filosofia, e que jamais fique á sombra do seu professor de Filosofia. É preciso filosofar. Surge a pergunta: Como isso é possível? No tópico a seguir mostraremos como é a estrutura do Café Filosófico e como o aluno experimenta os pensamentos dos filósofos sem reproduzi-los, dando movimento à Filosofia, ou seja, filosofando.

\title{
ESTRUTURA DO CAFÉ FILOSÓFICO
}

Quando falamos em estrutura do Café Filosófico, pensamos em um trabalho pedagógico, assim com as metodologias de ensino que o Professor Silvio Gallo sugere a prática pedagógica, assim como é proposto pelas Diretrizes Curriculares do Ensino de Filosofia e Sociologia (DCEs). O primeiro 
passo é a escolha do tema, os alunos da escola contribuem com sugestões de temas que gostariam de ser abordados no café. São feitas reuniões uma vez por semana para discutir toda a programação do evento, essas reuniões são todas registradas pelo diário de campo que os bolsistas fazem, o professor supervisor faz vídeos e fotos dessas reuniões. Depois é feita a pesquisa do tema a ser abordado no café, com textos filosóficos, livros, vídeos, o objetivo principal é a valorização da Filosofia no espaço escolar, criar espaço para que questões existenciais possam ser discutidas de forma tranquila, uma oportunidade maravilhosa para quem participa desse evento.

A comissão organizadora do evento, que é escolhida entre os alunos bolsistas, fica responsável por conseguir recursos para o lanche que será servido antes do evento, também por toda estrutura do evento, como convite dos alunos da escola, divulgação do evento, material para os participantes, cabe à comissão organizadora do evento informar aos convidados, alunos, professores, diretores, coordenadores tanto da escola quanto do projeto do PIBID, a data e o horário do evento. No dia do Café Filosófico, a comissão organizadora, prepara a sala, os materiais, lanche e faz uma vistoria para que tudo possa estar em perfeita harmonia e o evento aconteça de forma aprazível. Durante o Café filosófico são feitas fotos, vídeos e entrevistas com os participantes, tudo fica registrado no projeto e no canal $\mathrm{CM}$ da escola no Youtube, é registrado também nos diários de campos dos alunos bolsistas, textos com o tema são feitos pelos alunos da escola e alunos bolsitas e publicados no jornal Agora em parceria da PUC Goiás e o PIBID.

Ao projetarmos o Café Filosófico, imaginamos o aluno diante do filosofar, a autenticidade é muito importante, pois vivemos em dias em que parece que nada é para durar, a falta de interesse na leitura por parte de tantos alunos nas escolas, é preciso reconquistar isso. Essa é, principalmente, uma tarefa difícil. Pois, mudar a forma de pensar de uma pessoa, que muitas vezes está segura e convicta das suas ideias, crenças e valores, que não quer ver e nem ouvir o que está a sua frente, ou seja, o óbvio. Isso nos leva a compreender e a redescobrir na escola a concepção de espaço público, que é demarcado pela liberdade, sendo sua função preparar os alunos para exercer as ações políticas e sociais. Assegurar a liberdade de manisfetar, pensar, discordar, pensar a vida cotidiana, pensar com autonomia, aprofundar a reflexão, pois tudo isso está tão precário na 
atualidade. Os alunos que são convidados a participar do Café Filosófico, não vão com certezas, e sim com dúvidas e, isso é muito importante, pois a dúvida é uma aliada para que eles não se enganem, vão pensar e irão ver que isso pode ser um prazer, experimentam o conhecimento filosófico que os levam a filosofar.

Uma preocupação surgiu durante a preparação dos Cafés Filosóficos: como conciliar os temas trabalhados nos Cafés com os temas que o professor ministra em sala de aula? Os bolsitas do PIBID assistiram aulas dos professores que ministram a disciplina de Filosofia nas escolas, observaram os comportamentos dos alunos durante as aulas, e as metodologias utilizadas pelos professores. Os bolsistas observaram a realidade em sala de aula, investigaram os conteúdos ministrados e durante os intervalos conversaram com os alunos das escolas. Os bolsistas juntamente com estes escolheram temas ligados com conteúdos ministrados e que eram de grande interesse por parte dos alunos. Deixar os alunos da escola escolherem os temas foi um exercício de autonomia, pois eles estavam dispostos a aprofundar mais nos temas, não só durante os cinquenta minutos de aula, uma vez por semana, queriam mais conhecimento filosófico, colocando-se no processo de escuta, permitir que o outro possa expressar, partilhar conhecimento, compreendendo $o$ que é a alteridade, tolerância e valorizar as diferenças.

Como é possível o aluno experimentar os pensamentos dos filósofos sem reproduzi-los, dando movimento á Filosofia? Os Cafés Filosóficos contribuíram para o fortalecimento das leituras e análises prévias das obras que foram utilizadas durante a realização do evento de acordo com cada tema. Como no livro dos filósofos Deleuze e Guattari, os quais ressaltam que a Filosofia se fosse considerada uma ciência ou mesmo, uma forma de arte, seria a ciência ou a arte de criar conceitos, e este criar, segundo eles, possibilita aos estudantes da educação básica a experiência filosófica. A possibilidade de criarem seus próprios conceitos filosóficos a partir da reativação de outra filosofia, propiciada pelo estudo dos problemas filosóficos e da história da filosofia.

Os Cafés Filosóficos contribuíram e contextualizaram os conhecimentos filosóficos e fizeram os alunos criarem seus próprios conceitos. Lendo os textos filosóficos eles perceberam o problema levantado por cada filósofo, todo o vocabulário dos filósofos que para muitos é complicado, se 
tornou mais acessível e sem banalizar a Filosofia como foi bem colocado pela professora Lídia no seu livro. A ideia é motivar os alunos, apresentar o mundo dos conceitos, sendo a finalidade dos Cafés Filosóficos a autenticidade, mesmo sabendo que os jovens preferem o mundo digital, que muitos não interessam por textos longos. Como descreve o sociólogo polonês Zygmunt Bauman, no seu livro "Amor Líquido": "vivemos tempos líquidos, nada é feito para durar", até relações humanas são perecíveis, as relações se misturam e se condensam com laços momentâneos, frágeis e volúveis. Num mundo cada vez mais dinâmico, fluído e veloz. Seja real ou virtual. Nossa autenticidade foi roubada, nossa preocupação é resgatá-la. Quem foi convidado para o Café Filosófico, foi servido da maravilhosa experiência da reconquista da autenticidade, e com isso os alunos começaram a criar seus conceitos, puderam experimentar a capacidade do próprio pensamento, tiveram contato com pensamento dos filósofos, porém não reproduziu esses pensamentos, os alunos através da leitura e do estudo dos textos filosóficos puderam dar esse movimento á Filosofia.

\section{CONSIDERAÇÕES FINAIS}

Foi uma experiência marcante onde vivencia-se não somente a fascinação dos alunos pela filosofia, como também a importância da relação professor-aluno. Inicia-se com a introdução dos conteúdos filosóficos, com o pensamento de cada filósofo e percebemos certa dificuldade, devido ao uso das opiniões particulares. Algumas expressões, como por exemplo: "eu acho", "eu penso", "ou então o que você pensa?" Contribuem para o surgimento do senso comum, das opiniões, e até do pensamento dos filósofos, durante o Café Filosófico. Com isso os alunos puderam experimentar o saber filosófico e, como afirma os autores Gallo e Aspis, o professor deve levar em conta as experiências dos alunos, sempre avançando e superando o senso comum, fazer o aluno pensar, argumentar filosoficamente, pensar o mundo que se vive.

O projeto do Café Filosófico no ensino médio, com a finalidade de evidenciar no meio escolar a disciplina da Filosofia, os objetivos que estão nos Parâmetros Curriculares Nacionais, menciona que a Filosofia precisa permitir 
que o aluno possa ler textos filosóficos, através da escrita articular conhecimentos filosóficos, contextualizar esses conhecimentos, sendo que a finalidade principal foi reconquistar a autenticidade, fazer com que o aluno do ensino médio, possa pensar com autonomia, mesmo com tantas dificuldades que escola pública apresenta. A ideia é que o aluno possa experimentar os pensamentos dos filósofos, e que jamais fique á sombra do seu professor de Filosofia, pois o importante é filosofar.

Os novos contextos e desafios no processo de ensinar Filosofia no universo da escola pública proporciona á comunidade escolar espaço, tempo de reflexão, processo de leitura e escrita filosófica. Construção de novas metodologias no processo de ensinar e aprender a Filosofia. Trabalhar com objetivos voltados a produção do conhecimento do pensar, refletir é de suma importância no processo de construção do diálogo filosófico, no encontro as novas formas de cultura e comunicação, instituídas pelos jovens. Os filósofos franceses Deleuze e Guattari, orientam que a Filosofia é atividade onde o processo não se separa do produto, ou seja, só se faz Filosofia filosofando, e a melhor maneira de fazer isso é apresentando problemas que a Filosofia aponta.

O que se espera com esse trabalho é que a experiência desse projeto possa ser partilhada com profissionais da área e que possa também ser um incentivo para professores, mesmo que seja de áreas diferentes, uma metodologia de ensino que possibilita ser diferente das aulas formais, menos monótonas, inovação da prática docente e mais eficientes do ponto de vista da relação ensino-aprendizagem. Acredita-se que estas reflexões não se encerram aqui.

\section{REFERÊNCIAS}

BRASIL. Ministério da Educação e do Desporto. Secretária de Educação Média e Tecnológica. Parâmetros Curriculares Nacionais para o Ensino Médio. Brasília: MEC/SEMTEC, 1999.

SAUTET, Marc. Um Café para Sócrates: como a Filosofia pode ajudar a compreender o mundo de hoje. Tradução de Vera Ribeiro; Rio de Janeiro: Ed. José Olympio, 1997. 
ASPIS, Renata Lima. GALLO, Silvio. Ensinar Filosofia: um livro para professores. São Paulo: Alta Mídia e Educação, 2009.

RODRIGO, Lídia Maria. Filosofia em sala de aula: teoria e prática para ensino médio. Campinas - SP: Autores Associados, 2009.

DELEUZE, Gilles; GUATTARI, Félix. O que é a Filosofia? Tradução Bento Prado Jr. e Alberto Alonso Muñoz. São Paulo: Editora 34, 1992. 